This item was submitted to Loughborough's Research Repository by the author.

Items in Figshare are protected by copyright, with all rights reserved, unless otherwise indicated.

\title{
Product personalisation using personally meaningful data and the creation of new product attributes
}

\section{PLEASE CITE THE PUBLISHED VERSION}

http://dx.doi.org/10.1504/IJRAPIDM.2017.10003092

\section{PUBLISHER}

(C) Inderscience

\section{VERSION}

AM (Accepted Manuscript)

\section{PUBLISHER STATEMENT}

This work is made available according to the conditions of the Creative Commons Attribution-NonCommercialNoDerivatives 4.0 International (CC BY-NC-ND 4.0) licence. Full details of this licence are available at: https://creativecommons.org/licenses/by-nc-nd/4.0/

\section{LICENCE}

CC BY-NC-ND 4.0

\section{REPOSITORY RECORD}

Green, Cay, Samantha Porter, and Guy Bingham. 2019. "Product Personalisation Using Personally Meaningful Data and the Creation of New Product Attributes". figshare. https://hdl.handle.net/2134/24430. 


\title{
Product personalisation using personally meaningful data and the creation of new product attributes.
}

\author{
C. Green, Dr C. S. Porter and Dr G. Bingham.
}

Design School, Loughborough University, Loughborough, LE11 3TU, UK

c.green2@lboro.ac.uk1, C.S.Porter@lboro.ac.uk2, G.A.Bingham@lboro.ac.uk3

\begin{abstract}
Some Additive Manufacture processes can be used to fabricate personalised products. Commercial companies have formed that exploit this fabrication potential, creating co-design environments that allow users to personalise and customise product geometry in new ways. Work carried out at the intersection of art and design takes this a step further, exploring ways in which an objects form can be transformed using complex data sets. Interactions that facilitate product personalisation using data that is meaningful to the owner could stimulate the formation of Product Attachment, which in turn could extend a products lifespan. However, this new product personalisation potential could lead to the formation of new product attributes that must be mediated by both the designer and the user. This paper explores examples of product/data synthesis and uses them to propose three product attributes that could result from data driven Product Personalisation: Abstractness, Visibility, and Obtrusiveness.
\end{abstract}

Keywords: Additive Manufacturing; Product Personalisation; Product Attachment; Product Lifespan Optimisation; Product Design; Co-Design.

\section{Introduction}

The ideas presented in the following paper have formed alongside research into end user enacted Product Personalisation (PP) within the context of product fabrication using Additive Manufacture (AM) technologies, and the subsequent potential for the formation of Product Attachment (PA). This situates the research within the fields of product lifetime optimisation and resource efficiency. This paper describes the formation of potentially new product attributes that could arise in products that exploit the fabrication potential of AM. A conscious decision was made not to constrain the research by only considering the fabrication potential offered by current AM technologies. To do so would constrain the usefulness of the research findings into the future. It is hypothesised that fabrication technologies will continue to be developed that increase design freedom, with AM being the most obvious leader in terms of the flexible creation of product form. The Carbon M1 CLIP (http://carbon3d.com) process, with its increase in speed of production and surface finish, exemplifies the type of development envisaged.

AM can overcome some of the design considerations inherent in conventional subtractive or formative methods, leading to a greater degree of design freedom (Yang \& Zhao 2015). A good example of this is the design freedom that AM offers when compared to designing parts for fabrication using injection mould tooling. Non-tapered walls, sharp edges, non-uniform wall thicknesses, and 'over-hangs/under-cuts' are permissible using AM. These features would present significant challenges for injection mould tooling, requiring complex 
and expensive tools. This couple with the 'ability to virtually manufacture parts of any geometric complexity without tooling' (ibid) makes it ideally suited for the production of personalised products.

At the time of writing, using AM to fabricate most mass-market products, especially consumer durables, would be prohibitively expensive. In addition to cost of production, other disadvantages when compared to conventional manufacturing methods are limited material range, minimal wall thickness requirements, and the need for support material and its removal (Thomas 2010). Nevertheless, it is anticipated that innovation in AM technology will overcome some of these limitations, making AM a viable and cost effective route to market. This will allow designers to create mass-market products with transformation potential that exceeds existing product customisation and personalisation offerings.

This paper identifies work that exploits the fabrication potential of AM to mix data and geometry and create physical artefacts. Examples from both commercial sources and from art and design practitioners will be used to identify and describes the new product attributes resulting from this synthesis. It is the contention of this paper that these attributes will need to be considered by the designer when creating such mutable products, since they will confront the end-user both during the personalisation process, and through use and ownership of the resulting product. These attributes will inevitably affect on-going personal valuation of the product, the strength of the user/product bond, and subsequently affect the products lifespan.

\section{Examples of AM facilitated Product Fabrication:}

Companies have started to emerge that take advantage of the flexible fabrication potential of AM in order to offer individuals the opportunity to customise or personalise products prior to their fabrication (figure 1). Three such companies will be described here: Digital Forming (2014), Nervous Systems (2015), and Reify (2015).

The Digital Forming UCODO web site hosts products that have been created by designers and jewellery makers to afford some level of transformation by an end-user via UCODO's on-screen (in browser) interface. Before a product can be included on the UCODO web site, each designer must use Digital Forming software to create a series of deformations and/or customisations that can be applied to their product during the personalisation process. Examples of the types of deformation and customisation that the designer can include are:

- Setting the location of a deformation: focusing on a product feature or the whole product.

- Choosing the nature of the deformation: for example, linear scaling along and axis, inflation or deflation about a XYZ co-ordinate, twisting geometry around an axis.

- Setting the extents that each deformation can be applied.

- Specifying a location on the product at which text can be applied (in relief).

- Creating multiple variants of features, for example giving a choice of different types of lid on a teapot.

The deformations created for the product are assigned on screen controls such as sliders and radio buttons (see figure 1). These onscreen controls are laid out to form an interface that can be used by the end user to interact with the product on screen and in real time. The extent to which the products on the UCODO website exploit the flexible fabrication potential varies. Some offer only minimal transformation potential, whilst others 
allow the user to perform transformations that result in products that differ markedly from the 'seed' or 'starting' object.

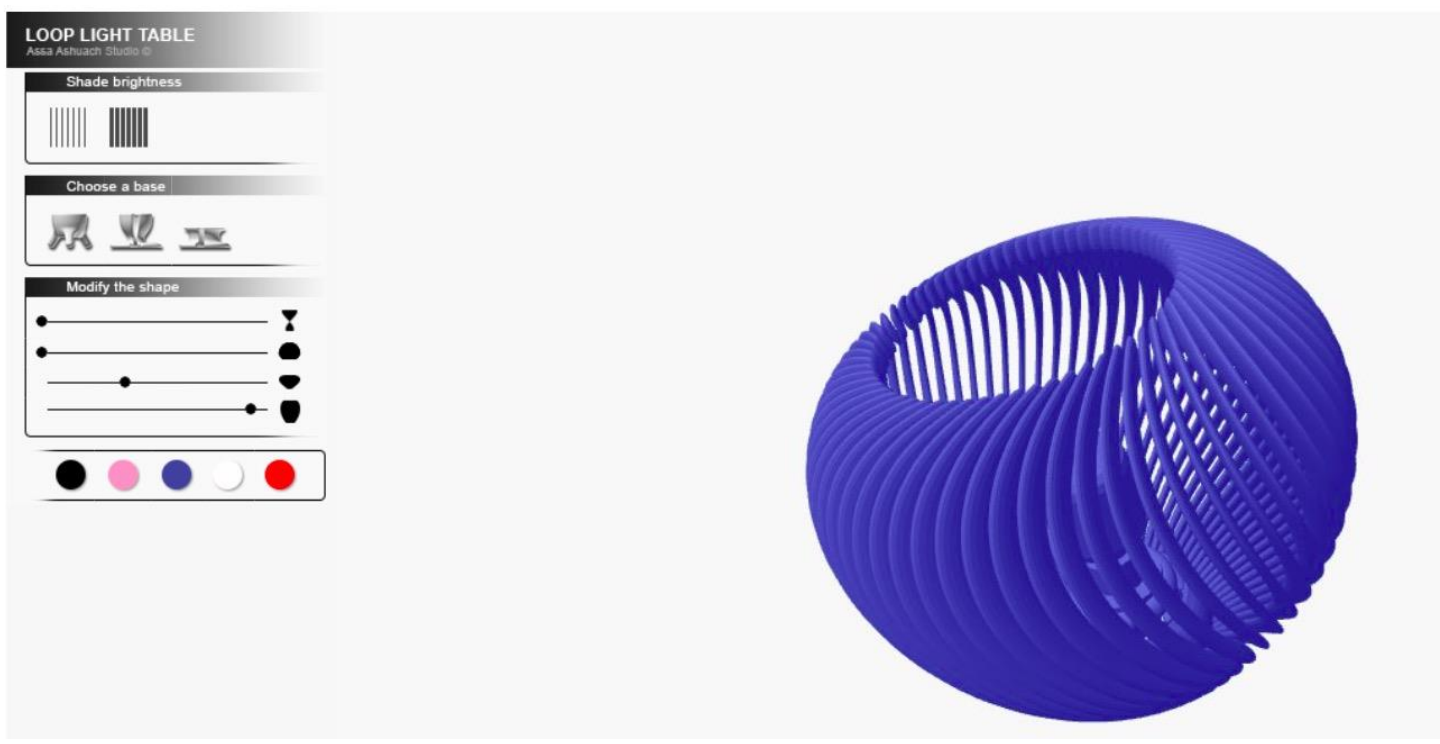

Figure. 1: Screen grab from the Digital Forming Store (2014.) showing product transformation interface (top left) and real-time rendering of product (Assa Ashuach Vase - right). From https://shop.digitalforming.com/assa-looplight-table-twist.html.

Another company exploiting the flexible fabrication potential of AM is Nervous System. Again they offer products that can be transformed by users via on-screen interface. However, Their approach differs from UCODO in that they use proprietary algorithms to generate the form of each of the products that they host on their website.

The products that Nervous System creates are inspired by forms and structures found in nature: coral exoskeletons and leaf venation are two examples. Again, users are invited to interact with the products via an on screen interface that consists of sliders and radio buttons (see figure 1), and again, changes are rendered in on screen in real-time. The changes made by the user are interpreted by the algorithm and product geometry altered accordingly.

In these two examples, (UCODO and Nervous System), user interaction is limited to the transformation of product geometry. The former facilitates this in a transparent manner: altering the position of an on-screen slider alters on-screen geometry by a proportionate amount. In the latter example, user alterations are mediated by an algorithm that computes geometry according to 'rules' that are hidden from the user. The next examples will describe projects that result in the creation of objects that have been transformed by a data set. 


\section{Data Driven Product Personalisation:}

The examples described in the previous section were developed in a commercial setting, and exploit the fabrication potential of AM to create personalised products. The same flexibility of fabrication has been explored in non-commercial settings to create functional (usable products) and non-functional objects (art pieces). Artists and Designers have used AM to create artefacts that mix data into their form, or objects that give form to data. A good example is the Love Project by Architecture practice EStudio Guto Requena in Brazil (2015). The project was set up as:

\section{'a study in design, science and technology that captures the emotions people feel in relating personal love stories and transforms them into everyday objects'}

For the project, participants were recruited and asked to recount the story of 'The Love of Their Life'. Whilst doing this, sensors collected data relating to the participants brain activity, galvanic skin response, heart rate, and voice (audio recording). Each of these data sets can be viewed as a waveform with the 'y' axis describing the value being measured, and with time as the ' $x$ ' (see figure 2). These waveforms were transformed into paths along which a shape could be extruded in order to create geometric data. The resulting forms are mirrored about planes arranged around a central axis creating cylindrical structures that form usable objects such as vases, lampshades and bowls (figure 3 ).

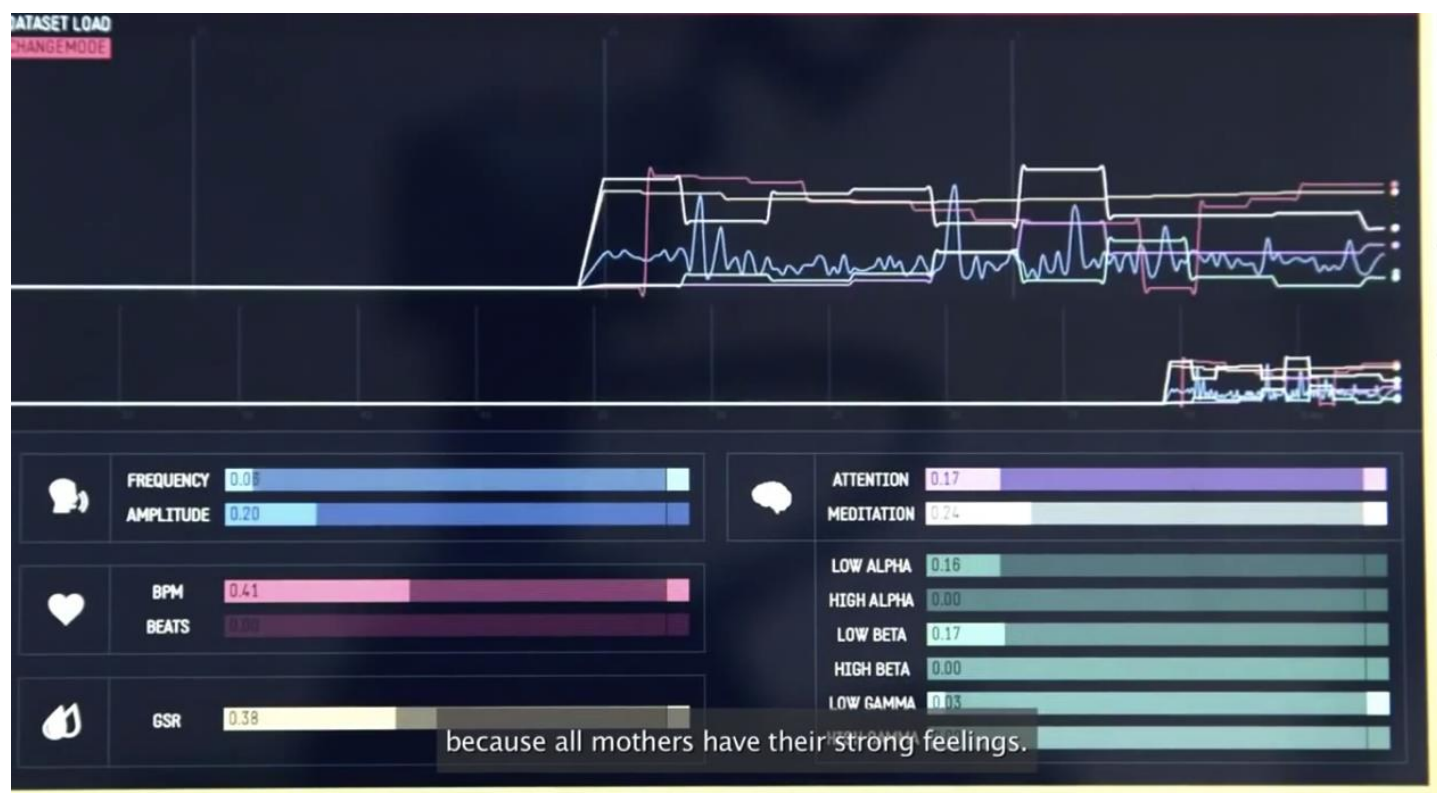

Writable $\quad$ Smart Insert $24: 5$;

Figure 2: Biometric data displayed graphically (The Love Project - Estudio Guto Requena).

The collected data appears to have been used to inform product form in a linear fashion; that is, data collected at the beginning of the participant's story is present at one end of the path (the base of a vase), and data relating to the end of the story will be present at the opposite end of the path (the rim of the top of a vase).

The resulting new geometry is given physical form via AM (figure 3). The result is an object whose form and function remains largely unchanged from that which the designer chose, i.e., a vase is still vase shaped and 
functions as a vase. Only the surface detail changes as a result of the application of the participant's 'bio-data'. Linear application of the bio-data allows the participant to connect changes in surface detail with key points in the story that they told. The object is a 'frozen' physical representation of their story.

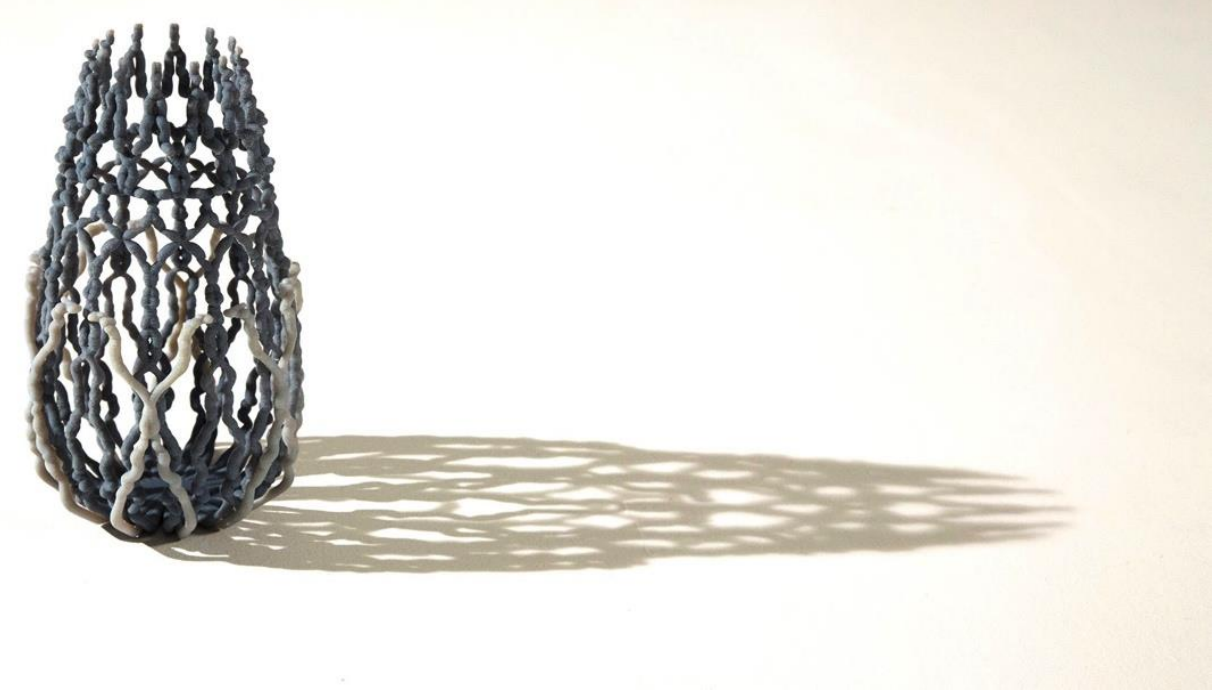

Figure 3: Additively manufactured vase (The Love Project - Estudio Guto Requena).

Other projects that use meaningful non-geometric data to transform the geometry of an object are Reify (2015) and Gilles Azzaro's 'Infant's First Cries' (Sher 2015). In these instances, audio is analysed with custom algorithms and transformed into three-dimensional data from which a 'sound sculpture' is additively manufactured (figure 4).

The techniques used in these three examples could be used to transform and therefore personalise everyday objects if AM was used as the means of fabrication. This would create new challenges and opportunities for designers, and also present new perceptual and interpretive challenges for both practitioner and end user. The designer, in creating a product and the interaction by which it can be transformed will need to consider the types of data that could be used, where on the product it can be applied, and set limits for the intensity of application in order for the product to remain functional and aesthetically congruent with their design intent.

Depending upon the design freedom granted to the user, the resulting personalised product could acquire characteristics that affect how it is used, both functionally and psychologically. It is hypothesised that one outcome of facilitating PP that uses data in ways described in the examples above, the likelihood of the formation of PA could be increased. This would be the result of linking the object with data that is meaningful to the user, and therefore making the object capable of stimulating memories of an event (Mugge et al 2004 and 2009). However, these novel personalisation processes could also cause a product to acquire attributes that could affect valuation. Three attributes resulting from these novel personalisation processes have been identified and given provisional working titles: Abstractness, Visibility, and Obtrusiveness. These will be discussed at the end of this paper, but first definitions of PP and PA will be presented. 

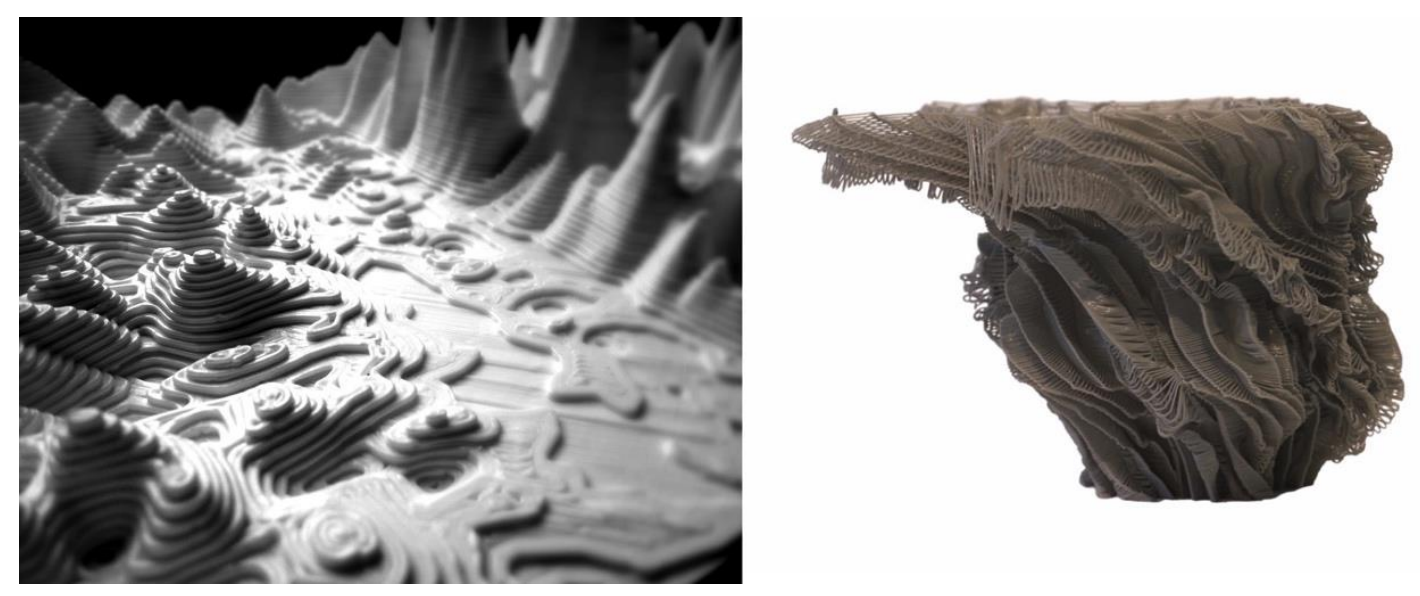

Figure 4: (left) 'Infants first cries' by Gilles Azzaro, (right) A sound sculpture created by Reify.

\section{Product Personalisation and Product Attachment:}

The two previous sections described different means of transforming object prior to their fabrication using AM. In the Digital Forming example, products are given unique forms using an onscreen interface to apply deformations to a mutable product form. In the Reify example, the objects form is entirely the result of the data chosen by the end-user: no object existed prior to selection of this data. In the 'Love Project' example, simple forms that described usable products existed prior to data collection. Their form is altered by the data in a way that could be described as personalisation.

Product Personalisation is defined as:

'a process that defines or changes the appearance or functionality of a product to increase its personal relevance to an individual' (Blom 2000)

Note that this is different to 'customisation' in that, customisation typically results in a product that could be relevant to a number of individuals (Zipkin 2001). This increase in 'personal relevance' can lead to the formation of an Emotional Attachment to an object (Jiménez 2007). And since the object in question is a product, this bond manifests as Product Attachment (Mugge 2007; Mugge et al. 2009). PA is defined as an emotional bond between an individual and a product, and the strength of the person-object relationship (Ball \& Tasaki 1992; Mugge \& Schifferstein 2006).

The formation of PA offers potential pro-sustainable outcomes via reduced resource use: PA can cause the user/owner to postpone dispossession and seek repair or refurbishment of a product when necessary (Van Nes \& Cramer 2006).

A bond between an individual and a particular instance of a product can form for a number of reasons. These can relate to:

- The physical properties of the product: Attachment can form as a result of valuing a products supreme aesthetic or functionality (Mugge 2007). 
- The symbolic meaning of a product: Attachments can form to products that allow an individual to differentiate themselves from a peer group through display of a product, or conversely, allow them to display affiliation to a group, can generate attachment (Wallendorf \& Arnould 1988; Kleine et al. 1995; Schultz et al. 1989; Solomon 1983).

- Finally, attachment can form to products that have the ability to stimulate positive memories (Mugge \& Schifferstein 2006; Wallendorf \& Arnould 1988; Belk 1990).

\section{User perceptions of a screen based PP interaction.}

In 2014, primary research by the author was completed using the UCODO product personalisation website. The investigation sought to understand how the PP potential on offer might stimulate the formation of PA. Research participants were tasked with selecting a product from a choice of five available on the UCODO web-store. They were then asked to transform the product using an onscreen interface and instructed that they should stop when they were satisfied with the results. Thematic analysis of interviews collected immediately after each participant interaction with the UCODO software found that 19 out of 26 expressed a desire to be able to engage in a greater level of PP than that offered by the interface. Here, 'level of product personalisation' refers to the degree to which an individual was able to change the form and/or function of a product using the tools included in the interface. That number included individuals $(n=5)$ who expressed a desire to bring something of their own choosing to the PP process. The perceived limitations of the interface affected valuation of every aspect of the interaction and resulting product, including reported attachment.

Not all products can be of supreme appearance or functionality - some products will always be average in these respects. Such products will typically only ever elicit feelings of satisfaction in their owners, and product satisfaction is no safeguard against premature product dispossession since no attachment is present (Mugge 2007; Mano \& Oliver 1993). An exception is average products that have over time, through use, through the context of their acquisition, or via associated events, become symbolic of a memory that is significant to the owner (Mugge 2007).

Increasingly, many aspects of our lives are measured, collected and stored digitally. Heterogeneous data is often collected ambiently by sensors in order to build a picture of the 'quantified self. Online environments play increasingly important roles in our social and family lives. The uptake and ubiquity of smart-phones has facilitated the collection of high quality audio and visual data. It would seem only a matter of time before such devices are capable of collecting three dimensional data via a process of environmental scanning (Google, 2016). Over time, in amongst this amassed data it is likely that there will be data that relates to memories that are of significance to an individual. Inspired by the examples described earlier that utilise data in the creation of physical objects, one can see opportunities for the blending of personally meaningful data with products in ways that could increase their personal relevance to an individual.

In the short term, such personalisations could be sufficiently novel in their aesthetic as to generate new product attributes. These attributes will need to be considered at the design stage in order to create products that remain within aesthetic and functional boundaries that are acceptable to the designer and codesigner/user alike. 


\section{New Product Attributes:}

When a new product is encountered, its visual form - geometry, dimensions, textures, colours, graphics, materials and detailing - are cognitively assessed at an aesthetic, semantic and symbolic level (Crilly et al. 2004). An aesthetic impression is created, the result of the sensation of how attractive we find a product. A semantic impression is formed based on what we think the product tells us about its function or mode of use. And a symbolic association is formed based on what we think the product tells us about its owner. Assessment at these three levels stimulates a cognitive appraisal that informs the affective potential of the product and our subsequent behaviour towards the product (approach/avoid) (Desmet, 2003).

Personalised products resulting from the synthesis of product form and data have the potential to possess aesthetic attributes that differ significantly from the visual references found in products manufactured using mature fabrication techniques. This non-alignment with the familiar product archetypes, metaphors, and conventions would represent a 'new aesthetic' that affects cognitive assessment. The resulting emotional responses could be positive or negative: dislike, disgust, indignation, or positive emotions such as attraction, design, and surprise (Desmet, 2003).

The following product attributes; abstractness, visibility and obtrusiveness, have been identified as attributes that could arise from the synthesis of a product with personally meaningful data prior to fabrication. They are presented here in nascent form. Their definition and content has taken form as a result of observational assessment of work encountered during secondary research carried out within a broader research project concerned with PP and AM, and though a process of designing products personalised for memory using personally meaningful data. The descriptions presented here are unlikely to be exhaustive. Further research will be required to fully understand their design implications. Findings from primary research carried out into PP using personally meaningful data that relate to these new product attributes will be offered for discussion at the end of this paper.

\section{Abstractness: articulate its meaning based solely on a visual assessment of an object. \\ It is hypothesised that the level of abstractness of the PP will be informed by: \\ - Cultural conformity. \\ - Data content. \\ - Semantic interoperability. \\ - The mode of data processing prior to application to a physical product.}

This characteristic relates to the symbolic obviousness of a data derived PP. It describes the degree to which somebody who does not know the 'story' of the data used in the personalisation could identify, understand or

For some products, personalisation is not unusual. We are accustomed to seeing certain products personalised with images of loved ones or graphical information that possesses symbolic meaning for the owner. The geographical, spatial, social and cultural context of their use helps the viewer interpret their meaning. For 
example, an object personalised with a photo of a child, and owned by a grandparent probably means that the child is a grandchild. The symbolism of the data - the image - would be clear.

Some data resists semantic interpretation. The level of abstractness will be affected by the extent to which the content of data used in a PP or transformation can be understood by the non-informed viewer. If textual data were used to personalise an object, perhaps by having it presented in relief wrapped around the outside of a product, lines from a poem would produce a different level of abstractness to the letters from an individuals DNA sequence (a sequence of T's, G's, A's and C's). The former contains information that can be decoded by the viewer, inviting the construction of meaning as it is consumed. The latter could only be interpreted as a whole at a symbolic level. Its content would be resistant to deeper interpretation other than recognising what the text represents.

The textural data described in the previous example contains commonly encountered symbols (alphanumeric). PP that uses data derived from an unconventional source would be much harder to interpret. Returning to the Love Project (2015) described earlier, the waveforms collected from a research participant and subsequently applied to a product are both semantically and symbolically opaque to the uninformed viewer. Such a viewer would be unlikely to make the conceptual leap necessary to identify that the crenelated fronds that make up a vase (figure 3) were transformed as a result of the application of data to their form. They would be equally unlikely to intuit the source and meaning of the data. The origin of the objects form would need to be shared in order for its meaning to become clear.

In the above example, the data is used to generate form in a proportional and linear way. Each frond that makes up one of the additively manufactured objects (vases, fruit bowl, lamp shade) is shaped by the application of data linearly along its length. At any point along its length, the geometry of the frond is determined by the amplitude of the waveform that was used to create it at a point in time. This enables a viewer who has been made aware of the nature of the data to be able to 'read' the object. For example, a frond with a particularly thick section at its tip could be interpreted as a site of high emotional activity if they are in possession of the relevant information about how the data was applied. In the case of the Reify (2015) object, because the means of data application is unknown (a proprietary algorithm is used to construct geometry from data), a granular interpretation of the data used is not possible. Some form of interpretative knowledge may be able to be constructed by viewing multiple variants of Reify objects whose source data (music track) was known. But immediate interpretation at any level other than purely aesthetic would be impossible.

The individual personalising the product is in control of how symbolically obvious the personalisation would be to the viewer based on their choice of data and the mode of its application to the product. They can choose to keep the meaning 'secret' or not. From a PA point of view, how 'symbolically obvious' a PP is could inform the strength of a user product bond since the originator of the personalisation might value their status as 'gatekeeper' of its meaning.

\section{Visibility}

Abstractness describes the symbolic obviousness of a product/data personalisation and the way in which meaning could be obscured through the choice of data or its processing prior to application. Visibility describes the literal visual degree to which a PP is visible to the viewer. A personalisation's visibility can be determined by the intensity of its application, site of application, or by the nature of the data used. 
Products are often personalised in order to display group affiliation/differentiation (Wallendorf \& Arnould 1988; Kleine et al. 1995; Schultz et al. 1989; Solomon 1983), display ownership to the owner and/or others (Mugge et al. 2004), or to incorporate information that is symbolic of a significant, usually positive, event (Mugge \& Schifferstein 2006; Wallendorf \& Arnould 1988; Belk 1990). AM facilitates the fabrication of products with personalisation that ranges from barely perceptible to visually obtrusive. Again, this sets up the possibility of creating a 'gatekeeper' role for the user/owner. A product transformed could be so subtle that only the owner would be aware of its existence. A third party would need to be made aware of its presence in order to have a chance of understanding its significance.

Visibility can share some of the qualities that inform abstractness. An object could be personalised in such a way that, although the transformation is in plain sight, only the individual who initiated the personalisation would know that it is, in fact, personalisation. An example of this mode of personalisation is present in the work of Mark Selby (2016) who created a device that could replicate a defect present in one object in additional objects. Mark used the device to replicate damage that occurred to a bowl (a chip in its rim that occurred during an emotionally charged event) in other objects belonging to the owner of the chipped bowl. This was done in order to create additional reminders of the event. The damage present in the new objects would be visible to any viewer, but its significance, or even the fact that it was the result of personalisation, would be hidden from the viewer without explanation. If an individual collected geometrical data (three dimensional scanned data) from their environment and applied it to a product during a PP interaction, depending upon the nature of the data collected, its presence in the host object may not be detectable without an explanation.

Using AM, the visibility of a PP could be taken to the extreme of it not being visible at all. The internal support structure of an object could be personalised using data chosen by the owner. Once fabricated, only the owner would know: the PP would be secret, completely hidden from view. The only way to access this information would be to break the product apart, thereby destroying it.

\section{Obtrusiveness}

Visibility describes the literal visual presence of a data driven PP. Obtrusiveness describes the effect that the application has on a products function. Here, function could relate to a products role as a technical (utility) or non-technical (social) object (Crilly 2010). It is hypothesised that the obtrusiveness of a PP that utilises data is determined by the location of its application, the nature of the data being applied, and strength of its application.

An example could be the application of data to an object in the form of a texture. If mapped onto the object with a subtle relief, the objects aesthetic and/or utility may only be slightly altered. However, as the texture's relief is increased, the object could become difficult to hold or use, or even become unstable, and the aesthetic of the original product radically altered.

In addition to the 'intensity' of application, the site of application would also be a factor in the obtrusiveness of a personalisation. If the data was applied in an area that affords physical contact, the object could become difficult to hold and use. Similarly, application to a location on a product that conveys information to the user could impair communication between object and user. A data driven personalisation that significantly alters 
the form of an object could disrupt the aesthetic intent of the original design, perhaps destroying 'readability' devised over many design iterations (See Klöcker 1980, in Vihma, 1995).

In addition to the location and 'strength' of application, the type of data being used could affect functionality and aesthetics. An example could be a personalisation that uses geographical data derived from a landscape topographically on the surface of a product. Rolling hills (soft) would have a different look and feel to a mountain range (ragged).

The extent to which data can be applied during a PP and the allowable locations of its application would need to be considered by the designer, both when designing the object and when designing the interaction by which the personalisation takes place.

\section{Product Personalisation for memory using personally meaningful data.}

Primary research has been carried out into the personalisation of 'every day' products (as facilitated by AM) that use data that relates to a cherished memory in order to understand the affect on reported PA, likelihood of repair, and dispossession behaviour. The research sits within a broader investigation into PP, PA, and product lifetime optimisation. Five everyday products and a corresponding personalisation were created (visual renderings, not physical models, see figure 5) and a short vignette written that describes the nature of the memory used, selection of data relating to memory, the events leading to product selection and personalisation, and a brief description of the PP process.

The study was not designed to generate insights into the boundaries of what might be acceptable in terms of the abstractness, visibility or obtrusiveness of a product/data synthesis. All of the personalisations were designed not to be in any way obtrusive, either functionally or visually, or to be hidden in the physical sense. Nevertheless, two products (the crockery set and the tea-pot) did elicit responses that indicated that the personalisation was visually similar to bespoke surface decoration, therefore indicating that the personalisation could be seen as being hidden in plain sight.

Participants were not explicitly asked about issues surrounding 'abstractness' since the research method used (Experimental Vignette Methodology) stated the nature of the data used (personal relevance, source) in the personalisation. Nevertheless, questions were asked about valuation of 'gate-keeper' status resulting from any perceived 'abstractness' or 'hiddenness' present in the PP. The study indicates that the affect of such attributes is neutral. The greatest indicator of the likelihood of the 'gate-keeper' disclosing the meaning of the personalisation was the relational status of the object viewer. 


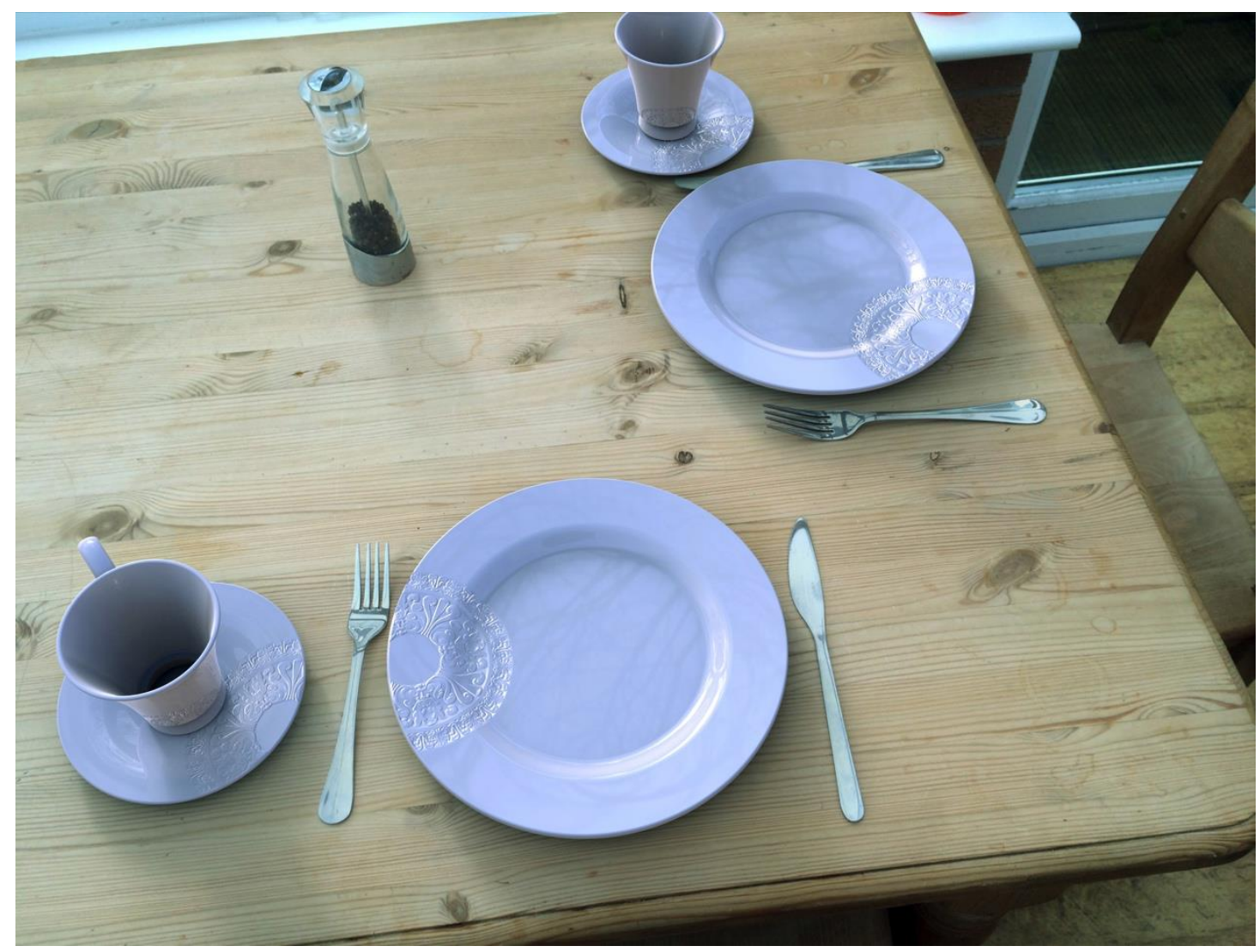

Figure 5: Additively manufactured plates incorporating three-dimensional scanned data of a cherished object chose and applied by the product creator and owner.

\section{Discussion}

The flexible fabrication potential of AM has seen the emergence of commercial and art lead projects that exploit this new manufacturing capability, exploring new product forms. This paper has described work that explores new modes of PP, either through direct manipulation of product geometry, the application of data to product geometry, or the creation of product geometries derived entirely from data. Analysis of this work has highlighted that the combination of AM's increased freedom of creation and the geometric possibility of product/data synthesis could lead to the creation of product with novel attributes. Three such attributes, abstractness, visibility and obtrusiveness have been presented here in nascent form.

Whilst PP interactions that facilitate the use of user generated meaningful data has the potential to create products with characteristics that align with those that determine the formation of PA, and could therefore potentially extend product lifespans, unconsidered use of AM and product/data synthesis could lead to the creation of products that fail to stand the test of time due to their unconventional aesthetic qualities, difficult product semantics, or impaired or overly specific functionality. This could result in products being discarded before the end of their useful (functional) life, either as waste or to the second hand market. This last outcome, 
whilst not ideal, could still see the product remain in use - Gregson and Crew (2003) have shown that some individuals value personalised objects for their ability to stimulate speculation about the products past life.

Further research is required to understand the implications of these new product attributes in order to formulate design strategies that exploit the fabrication potential of AM and new modes of product geometry formation in ways that seek to minimise the formation of attributes that could jeopardise product lifespans, and indeed, seek to optimise them.

\section{Reference:}

Digital Forming Store. [online] https://shop.digitalforming.com (Accessed 11 April 2016).

Ball, A.D. \& Tasaki, L.H., 1992. The role and measurement of attachment in consumer behavior. Journal of Consumer Psychology, 1(2), pp.155-172.

Belk, R., 1990. The role of possessions in constructing and maintaining a sense of past. Advances in Consumer Research.

Blom, J., 2000. Personalization: a taxonomy, New York, New York, USA: ACM.

Crilly, N., 2010. The roles that artefacts play: technical, social and aesthetic functions. Design Studies, 31(4), pp.311-344.

Crilly, N., Moultrie, J. \& Clarkson, P.J., 2004. Seeing things: consumer response to the visual domain in product design. Design Studies, 25(6), pp.547-577.

Desmet, P., 2003. A multilayered model of product emotions. The Design Journal. The Design Journal, 6(2), pp.1-13.

EstudioGutoRequena, Love Project. [online] http://www.gutorequena.com.br/site/work/objects/loveproject/29/ (Accessed July 22, 2015).

Gregson, N. \& Crewe, L., 2003. Second-hand cultures, Berg, London.

Google's Project Tango. [online] https://www.google.com/atap/project-tango/ (Accessed 11 April 2016).

Jiménez, F.R., 2007. Emotional Attachment to Objects: Proposed Antecedents . pp.1-17.

Kleine, S.S., suffix, R.E.K.S.I. \& Allen, C.T., 1995. How is a Possession "Me" or “Not Me?" Characterizing Types and an Antecedent of Material Possession Attachment. Journal of Consumer Research, 22(3), pp.327-343. 
Mano, H. \& Oliver, R.L., 1993. Assessing the Dimensionality and Structure of the Consumption Experience: Evaluation, Feeling, and Satisfaction. Journal of Consumer Research, 20(3), pp.451466.

Mark Selby Website. [online] http://markmakedo.co.uk/cv/ (Accessed 09/04/16)

Mugge, R., 2007. Product Attachment. Delft.

Mugge, R. \& Schifferstein, H.N.J., 2006. A longitudinal study on product attachment and its determinants. European advances in ....

Mugge, R., Schifferstein, H.N.J. \& Schoormans, J., 2004. Personalizing product appearance: the effect on product attachment, Proceedings of 4 th International ....

Mugge, R., Schoormans, J. \& Schifferstein, H.N.J., 2009. Emotional bonding with personalised products. Journal of Engineering ....

NervousSystem, [online] http://n-e-r-v-o-u-s.com (Accessed 11 April 2016).

Reify. [online] http://reifynyc.tumblr.com/?og=1 (Accessed July 22, 2015).

Schultz, S.E., Kleine, R.E. \& Kernan, J.B., 1989. “These are a few of my favorite things": Toward an explication of attachment as a consumer behavior construct. Advances in Consumer ....

Sher, D., 2015. Azzaro 3D Prints Infant's First Cries - 3D Printing Industry. Available at: http://3dprintingindustry.com/2015/07/31/sculptor-de-voix-gilles-azzaro-3d-prints-infantsfirst-cries/.

Solomon, M.R., 1983. The Role of Products as Social Stimuli: A Symbolic Interactionism Perspective. Journal of Consumer Research, 10(3), pp.319-329.

Thomas, D., 2010. The Development of Design Rules for Selective Laser Melting. pp.1-318.

Ucodo Web-store. [online] http://www.ucodo.com [Accessed April 2, 2015].

van Nes, N. \& Cramer, J., 2006. Product lifetime optimization: a challenging strategy towards more sustainable consumption patterns. Journal of Cleaner Production, 14(15-16), pp.1307-1318.

Vihma, S., 1995. Products as representations: An aesthetic study of design products., University of Art and Design Helsinki, Helsinki.

Wallendorf, M. \& Arnould, E.J., 1988. "My Favorite Things": A Cross-Cultural Inquiry into Object Attachment, Possessiveness, and Social Linkage. Journal of Consumer Research, 14(4), pp.531-547. 
Zipkin, P., 2001. The limits of mass customization. MIT Sloan Management Review, 42(3), pp.81-87. 